\title{
A Reconstruction of the Air-Sea Interaction Associated with the Weddell Polynya
}

\author{
G. W. K. Moore \\ Department of Physics, University of Toronto, Toronto, Ontario, Canada \\ K. Alverson \\ PAGES International Project Office, Bern, Switzerland \\ I. A. RENFrEW \\ Physical Sciences Division, British Antarctic Survey, Cambridge, United Kingdom
}

(Manuscript received 20 June 2000, in final form 8 October 2001)

\begin{abstract}
A recent major climatic event was the occurrence of approximately 350000 square kilometers of open water in the normally ice covered Weddell Sea near Antarctica during the winters of 1974-76. Within this polynya there was vigorous air-sea interaction resulting in the densification of the surface waters, a convective overturning of the water column, and the formation of large amounts of Antarctic Bottom Water. In order to further our understanding of this important event, the NCEP-NCAR reanalysis dataset is used to reconstruct the air-sea interaction associated with this polynya. The reconstruction shows that the polynya had a profound impact on the surface meteorology of the region. Surface air temperatures over the polynya were on the order of $20^{\circ} \mathrm{C}$ warmer than climatology. Total cloud cover over the polynya was $50 \%$ higher than climatology. The magnitude of the monthly mean sensible and latent heat fluxes during the winter months were on the order of 150 and 50 $\mathrm{W} \mathrm{m} \mathrm{m}^{-2}$, respectively, while precipitation was on the order of $1 \mathrm{~mm}^{-1 a y}{ }^{-1}$. Furthermore, the reconstructed airsea fluxes are highly variable in time with instantaneous values 5-10 times larger than monthly mean values. A cross-correlation analysis suggests that much of this variability can be attributed to the passage of transient synoptic-scale weather systems. The reconstructed buoyancy flux within the polynya during winter was on average negative, indicating that the surface waters were becoming denser thereby driving oceanic convection and Antarctic Bottom Water formation. Nevertheless there were instances when the buoyancy flux was positive. During these events, the freshwater flux due to precipitation was larger than the effect of cooling, thus resulting in a reduction in the density of the surface waters of the polynya. The integrated buoyancy flux over the winter period exceeds a previous estimate by $30 \%-40 \%$, suggesting that the oceanic convection that took place as a result of the existence of the polynya may have been significantly more vigorous than previously thought.
\end{abstract}

\section{Introduction}

During the austral winters of 1974-76, a large region of open water or polynya was identified in the center of the normally ice covered Weddell Sea (Gordon 1978; Carsey 1980). In a polynya, the absence of sea ice exposes the relatively warm surface waters to the cold polar atmosphere, which can lead to an intense exchange of heat and moisture between the ocean and atmosphere (Smith et al. 1990). In the case of the Weddell polynya, it is thought that this exchange resulted in a convectively driven overturning of the water column that produced a significant volume of Antarctic Bottom Water, a dominant water mass of the world oceans (Gordon 1978).

Corresponding author address: Dr. G. W. Moore, Department of Physics, University of Toronto, 60 St. George Street, Toronto, ON M5S 1A7, Canada.

E-mail: moore@atmosp.physics.utoronto.ca
Observations show that this large infusion of relatively cold and freshwater has now propagated into the South Atlantic Ocean (Coles et al. 1996). Although it has not reappeared in the intervening years, there is data to suggest the occurrence of a polynya in this region during the winter of 1960 (Gordon 1982). Furthermore, there is recent oceanographic data that suggests the region may be again primed for the redevelopment of a polynya (Gordon 1997). The possibility of an episodic occurrence of the polynya and concomitant oscillation in Antarctic Bottom Water formation may be a major source of climate variability on the decadal to centennial timescale (Gordon 1981; Coles et al. 1996; McPhee et al. 1996; CLIVAR 1997).

The oceanography of the Weddell polynya has received considerable attention (Gordon 1982; Motoi et al. 1987; Gordon and Huber 1990; Martinson 1991; Akitomo et al. 1995; Alverson and Owens 1996). The same 
cannot be said of the meteorology and in particular the air-sea interaction that was associated with the polynya. The oceanic convection that took place was most likely forced by air-sea fluxes of heat and moisture. This lack of attention has resulted in uncertainty regarding important aspects of the processes of oceanic convection as they occurred within the polynya (Gordon 1981; Martinson et al. 1981; Gordon 1982). This paper represents the first attempt to redress this situation and to provide quantitative information regarding the air-sea interaction associated with the Weddell polynya. This is of interest in its own right, but is made even more important by the large and relatively unknown climate signal that resulted from the oceanic convection forced by this interaction. We therefore also calculate the impact that this atmospheric forcing would have had on the density of the surface waters within the polynya.

We make use of the reanalysis dataset produced jointly by the National Centers for Environmental Prediction (NCEP) and the National Center for Atmospheric Research (NCAR). Reanalyses make use of techniques originally developed to initialize numerical weather prediction models to assimilate historical data with the goal of producing time series ideal for short-term climate monitoring and research (Kalnay et al. 1996). The NCEP-NCAR reanalysis uses the data assimilation system operational at NCEP in January 1995 and covers the period from 1948 to the present with fields available every 6 hours. Sea ice concentration is included as a part of the surface boundary conditions in the reanalysis. During the mid 1970 s, the sea ice concentration data were provided as monthly mean fields derived from the U.S. Navy/NOAA Joint Ice Center operational analysis (R. Grumbine, 1999, personal communication). For reasons that are unclear, the August 1974 sea ice field included in the reanalysis does not contain the polynya even though it is included in the original analysis from which the field is derived (Martinson et al. 1981). This omission compromises the reanalysis fields in the region of the polynya during the period of most intense airsea interaction that took place in 1974. Our focus therefore is on 1976 although we summarize results for 1975 as well.

In addition to the standard fields found in a conventional meteorological analysis, the NCEP-NCAR reanalysis includes fields derived from short-term forecasts such as the surface sensible and latent heat fluxes, the precipitation rate, net shortwave and longwave radiation. There is concern that these latter fields, which are not constrained to be consistent with observations, may not be representative of actual conditions. In particular systematic problems have been identified in the precipitation and turbulent heat flux fields in the NCEPNCAR reanalysis.

The NCEP-NCAR reanalysis precipitation field in high latitudes has many quasi-stationary features that appear to be correlated with the orography. Cullather et al. (1996) suggested that these features were the result of spectral noise. Subsequently, Moorthi (1997) demonstrated that the problem was in fact the result of an approximation used to determine the diffusion of moisture in the boundary layer. This is exacerbated at high elevations in the polar regions where specific humidity is small compared to the global mean and can result in spurious sources and sinks of freshwater. Accordingly, over the Southern Ocean, the magnitude of these anomalies is much smaller than over the Antarctic continent (Cullather et al. 1996). Notwithstanding these problems, Cullather et al. (1998) in their comparison of Antarctic precipitation estimates from a variety of datasets that included the NCEP-NCAR reanalysis, concluded that there was general agreement on the main features of the precipitation field in the region.

Renfrew et al. (2002) showed that for winter conditions in the Labrador Sea, which are similar to what took place over the polynya, the NCEP-NCAR reanalysis was in reasonable agreement with observations with respect to the surface-layer meteorology. However, the turbulent heat flux fields from the reanalysis were much larger in magnitude than the same fields derived from observations using the well established bulk algorithm of Smith (1988) with exchange coefficients updated to those recommended by DeCosmo et al. (1996). This algorithm had in turn been validated with turbulent heat flux measurements from the same research cruise. Renfrew et al. (2002) attribute this discrepancy to an inappropriate roughness length parameterization in the reanalysis. For this reason, this reconstruction makes use of the surface fields from the reanalysis to derive new sensible and latent heat flux fields following Smith (1988) and DeCosmo et al. (1996).

The radiation fields are also problematic. Walsh and Chapman (1998) have shown that neither the NCEPNCAR nor the European Centre for Medium-Range Weather Forecast (ECMWF) reanalysis captures the seasonal cycle of cloudiness over the Arctic Ocean. On the other hand, the NCEP-NCAR reanalysis does capture the correlation between cloudiness and surface temperature. We know of no similar comparison over the Southern Ocean. Fortunately the radiative fluxes over the polynya were substantially smaller in magnitude than the sensible and latent heat fluxes.

There is concern regarding the ability of any analysis to accurately represent the meteorology in data sparse regions such as the Southern Ocean. In this regard, the Weddell Sea during the mid 1970s was relatively well covered as there were four operational upper-air stations along the Antarctic coastline: Faraday, Halley Bay, SANAE, and Syowa. In addition, radiosondes were also being launched on a regular basis from Gough and Marion Islands to the north and northeast respectively of the region of interest. An even denser network of surface observations was available in the region. This is corroborated by Hines et al. (2000) who have identified some artificial long-term trends in the NCEP-NCAR reanalysis surface pressure field over the Southern 
Ocean. They state, however, that in the Weddell Sea region the reanalysis surface pressure field agrees reasonably well with observations from 1970 onward. In addition, we have compared observations from a buoy in the Weddell Sea with the NCEP-NCAR reanalysis during 1991 (not shown) and found good agreement with respect to the surface fields.

It is within this context that we believe that the NCEP-NCAR reanalysis fields provide the best available dataset with which to reconstruct the air-sea interaction that took place within the Weddell polynya of the mid 1970s.

\section{Air-sea interaction within the 1976 Weddell Polynya}

Figure 1 shows the monthly mean sea ice edge in the Weddell Sea for July, August, and November 1976 as depicted in the NCEP-NCAR reanalysis dataset. As noted by Carsey (1980), the formation of the polynya appears to have been a two-stage process. As the ice pack expanded in the austral fall, an embayment formed in the region where the sea surface temperatures remained above freezing (Fig. 1a). Continued expansion of the pack eventually surrounded the region of anomalously high SSTs, resulting in the formation of the polynya (Fig. 1b). The polynya remained ice free throughout the winter due to the transfer of heat from the deep ocean to the surface that occurred as a result of oceanic convection. Early spring meltback of the ice pack in the region (Fig. 1c), which unlike the polynya occurs almost every year, is another indicator of high oceanic heat fluxes in the region.

It is of interest to contrast the meteorological and airsea flux fields over the polynya with those that occur when no polynya is present. This will be accomplished by the consideration of monthly mean fields for 1976 as reconstructed from the NCEP-NCAR reanalysis with the corresponding climatological, that is, nonpolynya, fields ${ }^{1}$ at a location in the center of the region in which the polynya formed that year $\left(67^{\circ} \mathrm{S}, 15^{\circ} \mathrm{W}\right)$. The monthly mean fields were computed from the 6-hourly fields. Measures of the interannual variability, which in this case are taken to be the standard deviation of the monthly means about the climatological means, are also indicated. As discussed above, we have used the surface fields from the NCEP reanalysis and the Smith (1988)/ DeCosmo et al. (1996) bulk algorithm to calculate the sensible and latent heat fluxes.

Figure 2 compares fields that provide information on the meteorological conditions over the polynya as compared to nonpolynya years. Figures $2 \mathrm{a}, \mathrm{b}$ show the 2-m air temperature and total cloud cover. During the period January-March, conditions during 1976 were similar to the climatology. This is not unexpected given that, dur-

\footnotetext{
${ }^{1}$ The climatological values used in this paper are computed from the reanalysis data for the nonpolynya years 1980-98.
}
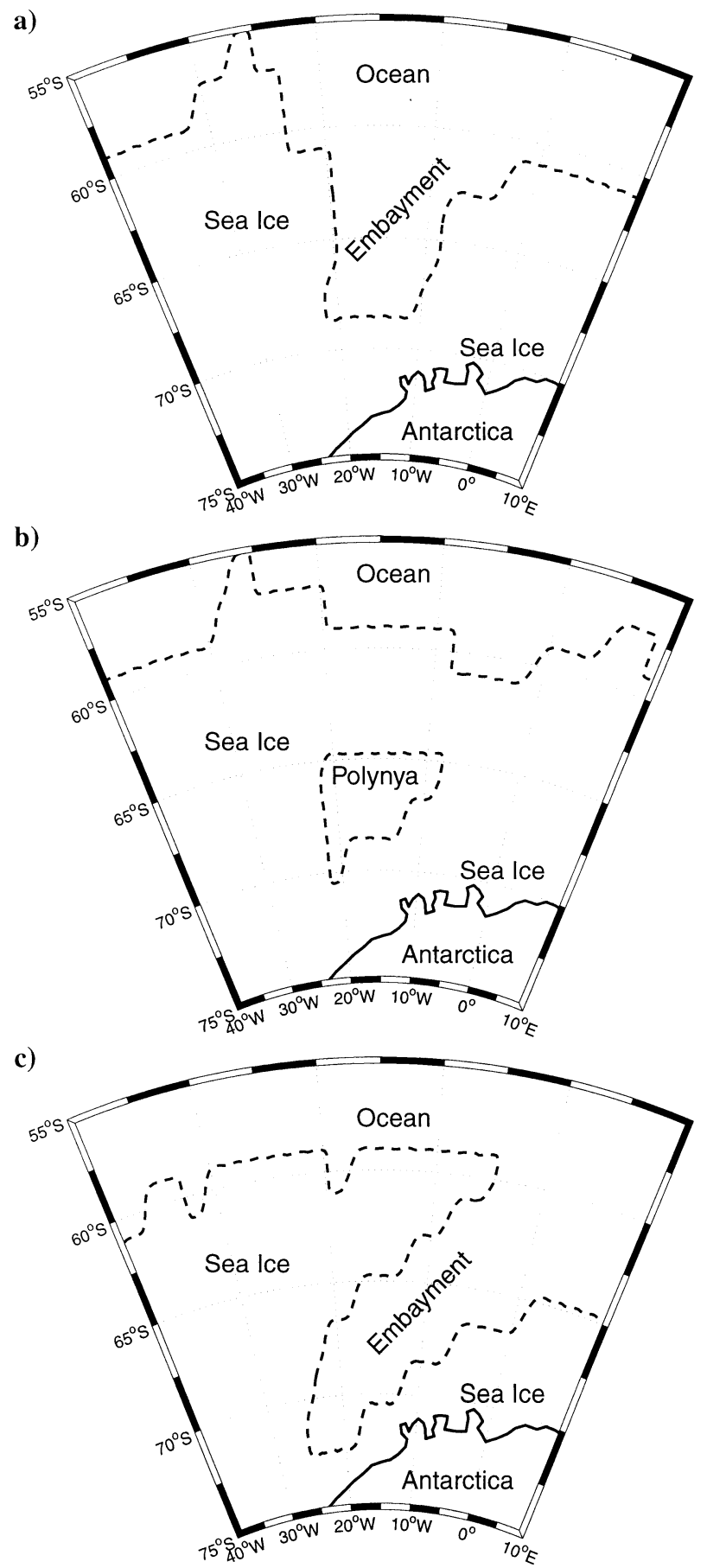

FIG. 1. Monthly mean sea ice edge (dashed line) in the Weddell Sea for (a) Jul, (b) Aug, and (c) Nov 1976 as depicted in the NCEPNCAR reanalysis dataset.

ing this period of the year, the location under consideration is typically icefree. From April onward, there is a divergence in the conditions during 1976 as compared to climatology. The 2-m air temperatures over the polynya were significantly warmer and the total cloud cover was greater than what occurs during nonpolynya 
a)
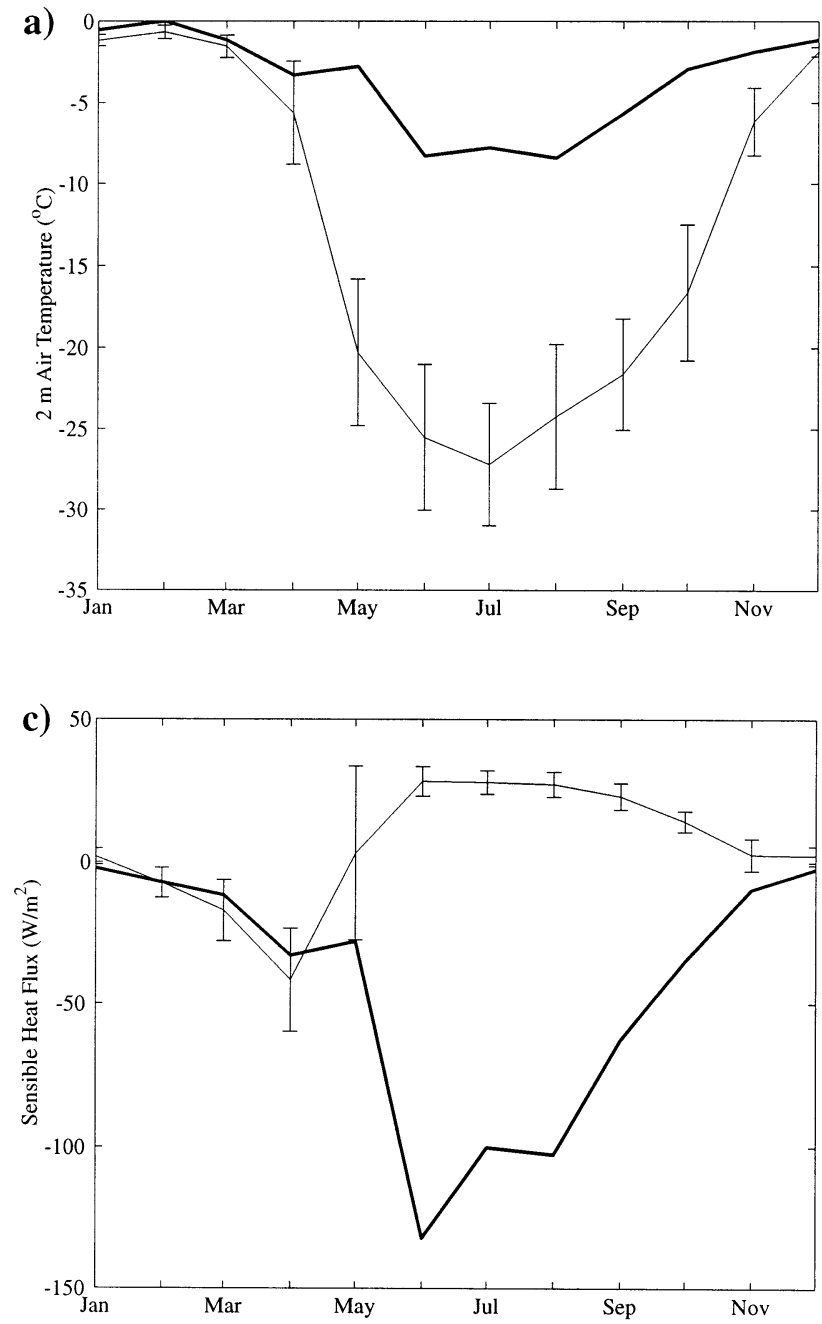

b)

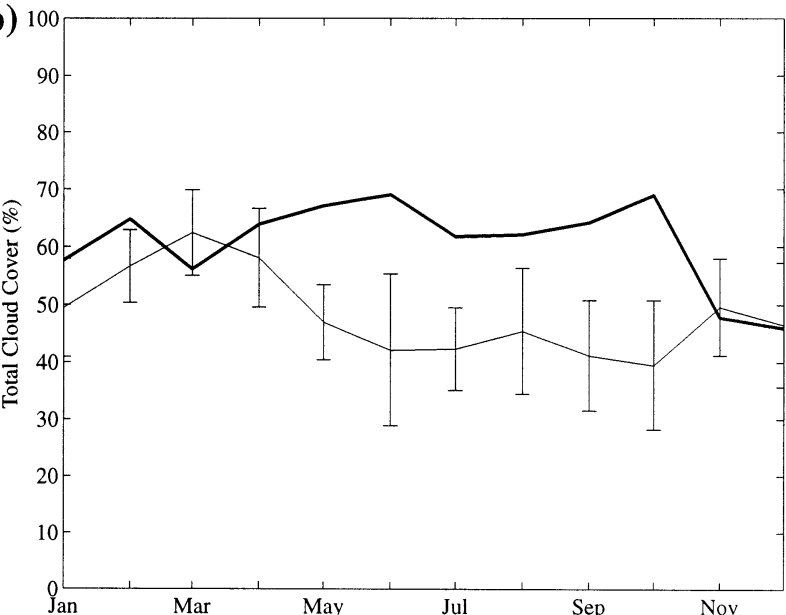

d)

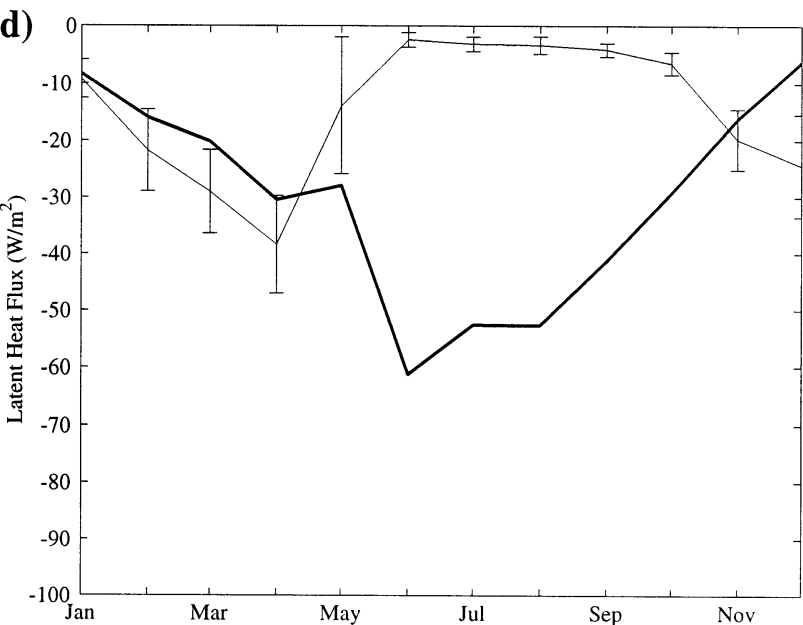

e)

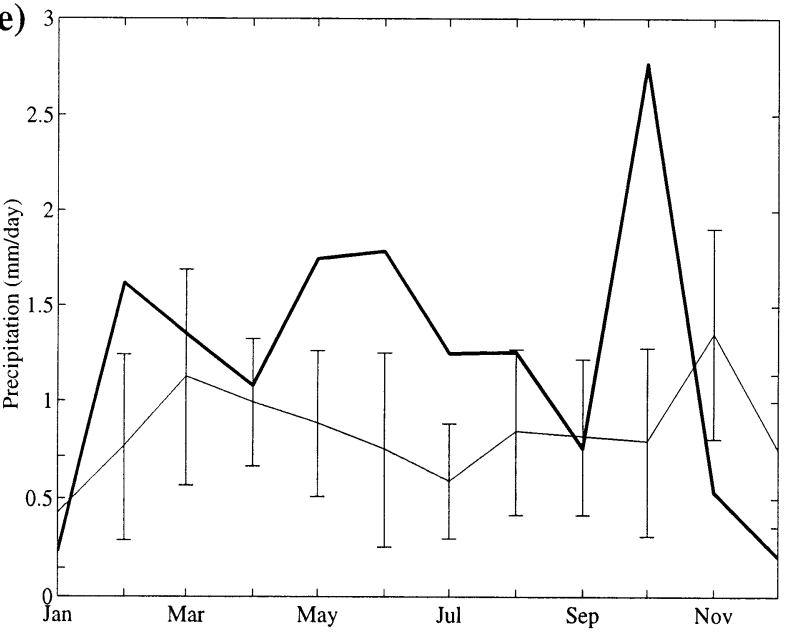

f)

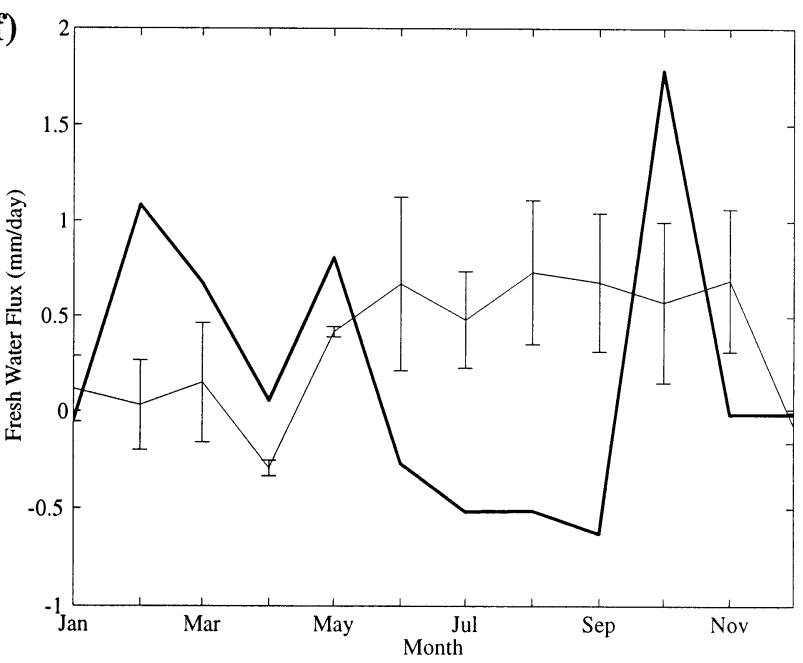

FIG. 2. Monthly mean values of the: (a) 2-m air temperature $\left({ }^{\circ} \mathrm{C}\right)$, (b) total cloud cover $(\%)$, (c) sensible heat flux (W m $\left.{ }^{-2}\right)$, $(\mathrm{d})$ latent heat flux $\left(\mathrm{W} \mathrm{m}^{-2}\right)$, (e) precipitation rate $\left(\mathrm{mm} \mathrm{day}^{-1}\right)$, (f) freshwater flux $\left(\mathrm{mm} \mathrm{day}^{-1}\right)$, (g) net longwave flux (W m $\left.{ }^{-2}\right)$, and (h) net shortwave flux $\left(\mathrm{W} \mathrm{m}^{-2}\right)$ at $67^{\circ} \mathrm{S}, 15^{\circ} \mathrm{W}$. The thin lines are the monthly means over the period 1980-98 as calculated from the NCEP-NCAR reanalysis. Standard deviations around these means are also shown. The monthly mean values from the NCEP-NCAR reanalysis for 1976 are plotted as the thick lines. 

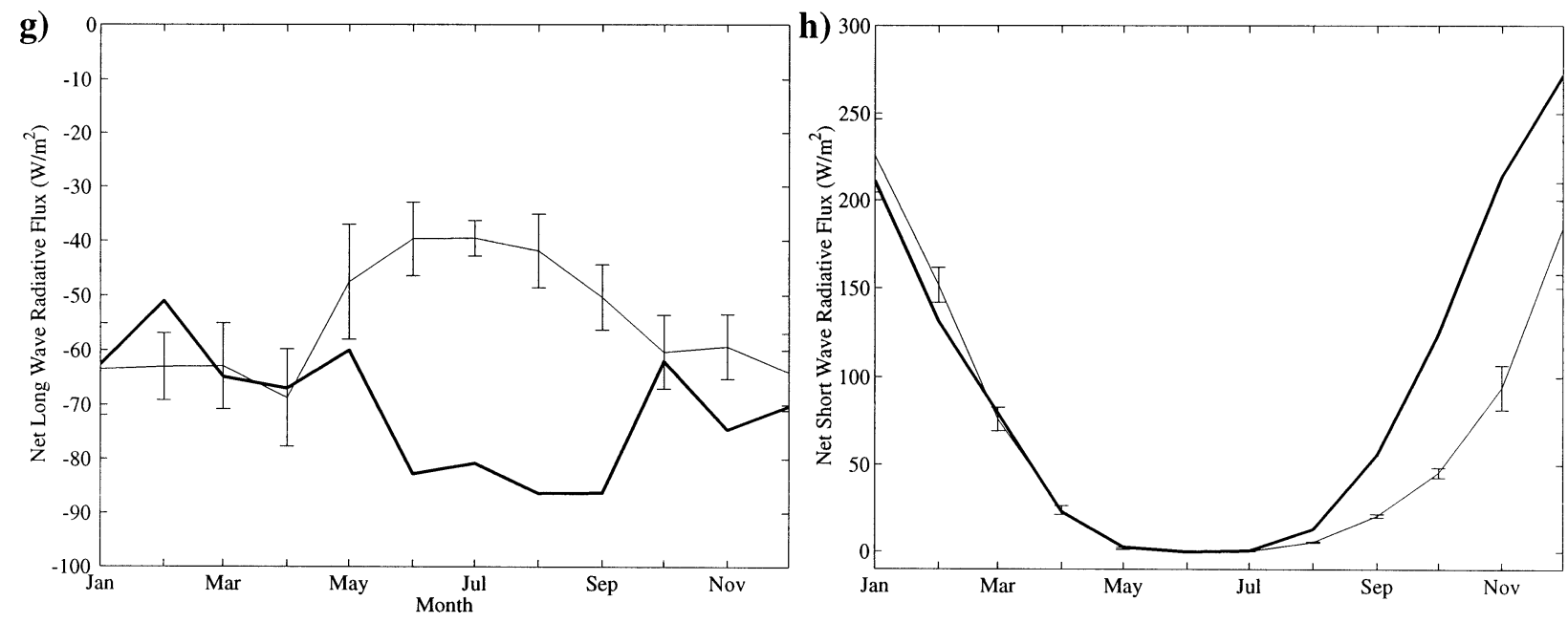

FIG. 2. (Continued)

years. This is consistent with the fact that during 1976, open water was present at the surface rather than sea ice. The increase in cloud cover is also consistent with the satellite imagery over the Weddell and other polynyas that indicates the presence of convective clouds (Carsey 1980). During the final months of 1976, when there is open water present even in the nonpolynya years, the fields return to values within the climatological range.

Figures $2 \mathrm{c}, \mathrm{d}$ presents a similar comparison for the turbulent heat flux fields. ${ }^{2}$ The surface cooling that occurred early in 1976 was similar to climatology. The climatological maximum in surface cooling occurs in April, after which the expanding sea ice cover reaches this location and decouples the ocean from the atmosphere for the remainder of the winter. Variability in the date at which sea ice reaches this location results in the large interannual variability in the turbulent heat fluxes during April and May. The dramatic impact that the absence of sea ice during 1976 had on the turbulent heat fluxes is most evident from May through to October. The magnitude of the monthly mean sensible and latent heat fluxes were in excess of 100 and $50 \mathrm{~W} \mathrm{~m}^{-2}$ during June, July, and August of 1976. As was the case with the other fields, the turbulent heat fluxes returned to values in line with climatology late in the year.

A similar comparison is made in Figs. 2e,f for the precipitation and the precipitation minus evaporation fields. ${ }^{3}$ According to the reanalysis, more precipitation

\footnotetext{
${ }^{2}$ In this paper, we use the conventional oceanographic definition that a cooling of the surface corresponds to a negative heat flux.

${ }^{3}$ Over the polynya, the freshwater flux experienced by the ocean is, ignoring processes such as the formation and melting of sea ice and deposition of wind blown snow, simply precipitation minus evaporation. In the presence of sea ice, as is the usual case over the Weddell Sea during winter, the freshwater flux at the surface of the sea ice is simply the rate at which precipitation fell. On the other hand, the freshwater flux felt by the ocean is a complicated function of sea ice growth, brine drainage and basal ice melt.
}

fell over the polynya during 1976 than one would expect from climatology. The additional source of moisture due to the open water of the polynya was most likely responsible for this enhanced precipitation. This is consistent with the warmer air temperatures and cloud cover over the polynya (Figs. 2a,b). Despite this, the monthly mean precipitation minus evaporation field was negative during most of the austral winter of 1976. This occurred because of the evaporation (Fig. 2d) that was taking place over the polynya. As a result, the salinity of the surface waters within the polynya was increasing during the year. October 1976 was an anomalous month during which a large amount of precipitation fell and as a result, precipitation exceeded evaporation resulting in a freshening of the surface waters.

Finally, Figs. 2g, h compares the net longwave and shortwave radiative fluxes over the polynya with climatology. ${ }^{4}$ Throughout the austral winter of 1976, the net longwave radiative flux was approximately $40 \mathrm{~W}$ $\mathrm{m}^{-2}$ more negative than the corresponding climatological values. This reflects the warmer surface temperatures that occurred as a result of the presence of the polynya, as compared to an ice covered surface, and hence the larger magnitude of the emitted longwave radiation. It should be noted that the increased cloud cover over the polynya (Fig. 2b) would have also affected the surface radiation budget. However in the NCEP reanalysis, this effect is secondary to that induced by the change in surface conditions. The net shortwave radiative flux at a fixed location is to first order a function of time and surface albedo. Throughout the first half of 1976, the net shortwave flux is similar to climatology. During the austral winter, the polynya was in polar night and the net shortwave flux was zero. The return of the sun in August resulted in a net shortwave

\footnotetext{
${ }^{4}$ The sign convention used is the same as that for the heat fluxes, that is, a negative radiative flux results in a cooling of the surface.
} 
flux that was significantly larger in magnitude than climatology. This is a result of the lower albedo of the polynya as compared to the normally ice covered surface and hence an increase in the magnitude of the absorbed shortwave radiation.

Figure 3 shows the August 1976 monthly mean anomalies of various surface fields as reconstructed from the NCEP-NCAR reanalysis. This figure confirms that the polynya had a dramatic impact on the mean atmospheric circulation in the region. The sea level pressure over and downstream of the polynya was $6-8 \mathrm{mb}$ lower than the long term mean for August. To put the magnitude of this anomaly in context, it should be noted that the interannual variability in sea level pressure in this region during August is on the order of $4 \mathrm{mb}$. The anomalously low sea level pressure resulted in convergence of the low-level wind field over the polynya. The negative sea level pressure anomaly and low-level convergence is consistent with modeling studies of the atmospheric response to an area of open water surrounded by sea ice (Alam and Curry 1995; Dare and Atkinson 1999). It is also consistent with the enhanced cloud cover (Fig. 2b) over the polynya. Surface convergence would be expected to advect sea ice into the polynya. As the ice melts, the freshwater input would tend to inhibit convection, destabilizing the polynya. This is in contrast to Martinson et al. (1981), who had previously stated that one would expect divergence in the surface wind field, which would act to stablize the polynya. The anomaly in the total turbulent heat flux, defined as the sum of the sensible and latent heat fluxes, is focused over the polynya with the largest anomaly situated along its western boundary due to the prevailing westerly wind. This asymmetry may have lead to enhanced oceanic convection on the western side of the polynya, contributing to its observed westward drift (Carsey 1980). There are also anomalies in the total turbulent heat flux field along $57^{\circ} \mathrm{S}$ in regions where the ice edge differed from climatology. The anomaly in precipitation rate was focused over the polynya with maxima along the western and eastern boundaries.

Figure 4 shows time series of the 6-hourly total turbulent heat flux and freshwater flux at $67^{\circ} \mathrm{S}, 15^{\circ} \mathrm{W}$ as reconstructed from the NCEP-NCAR reanalysis during the austral winter (May-September) of 1976. Both fields show considerable high frequency variability with peak fluxes much larger in magnitude than the monthly mean values. The magnitude of the peak total turbulent heat flux is in excess of $500 \mathrm{~W} \mathrm{~m}^{-2}$ while that of the freshwater flux is in excess of $15 \mathrm{~mm}$ day $^{-1}$. Figure 5 shows the surface fields in the vicinity of the polynya during an event in which the total turbulent heat flux was large and negative (1800 UTC 8 August 1976), and one in which the freshwater flux was large and positive (0600 UTC 19 August 1976). Both events were associated with the passage of synoptic-scale weather systems. On 8 August, a 960-mb low was located to the east of the polynya while a weak ridge was situated to the west.
The resulting cyclonic circulation advected cold and dry air off the Antarctic Continent over the relatively warm waters of the polynya resulting in a large transfer of heat from the ocean to the atmosphere. On 19 August, a 970-mb low was situated to the west of the polynya and the precipitation associated with the system's cold front was falling over the polynya.

To quantify the role that synoptic-scale weather systems play in modulating the air-sea fluxes over the polynya, we have computed the cross-correlation of a variety of fields with the total turbulent heat flux into the atmosphere and the precipitation over the polynya. The location chosen as being representative of conditions over the polynya is that $\left(67^{\circ} \mathrm{S}, 15^{\circ} \mathrm{W}\right)$ used in Figs. 2 and 4 . The cross-correlations were computed using the 6-hourly fields over the months of May to September 1976. The statistical significance of the cross correlations was determined with the one-sided Student's t-test (Kachigan 1991). In order to account for the autocorrelation of the fields on short timescales, the number of degrees of freedom used in the determination of statistical significance was reduced by a factor of 4 . The cross-correlations are only shown at those locations for which they are statistically significant at the $95 \%$ confidence level. As we shall see, the composite fields are mutually consistent and pass this test over a large geographical region providing one with additional evidence as to the statistical significance and physical relevance of the results. The resulting sets of cross-correlations for 2-m air temperature, 10-m winds, and sea level pressure are displayed in Fig. 6. Both sets clearly show large areas of statistical significance and spatial coherence that suggests that the temporal variability identified in Fig. 4 is associated with well-defined and coherent atmospheric flow regimes.

Figure $6 \mathrm{a}$ indicates that the cross-correlation of the sea level pressure field throughout the region with the total turbulent heat flux over the Weddell polynya has a dipole structure with a region of positive correlation to the west and a region of negative correlation to the east. That is, instances in which there was a transfer of heat from the ocean into the atmosphere over the polynya tended to occur when there was a region of high surface pressure to the west and a region of low surface pressure to the east. The anticyclonic flow about the high when combined with the cyclonic flow about the low would lead to strong southwesterly flow over the polynya. This is confirmed by the cross-correlation of the surface wind field with the total turbulent heat flux into the atmosphere that shows the advection of cold and dry air from the Antarctic continent over the open waters of the polynya. In contrast, Fig. $6 \mathrm{~b}$ indicates that the atmospheric flow regime associated with precipitation events over the polynya was markedly different. The precipitation events were correlated with a region of low pressure just to the west of the polynya. The cyclonic flow around this region would advect moist midlatitude maritime air over the polynya where it 
a)
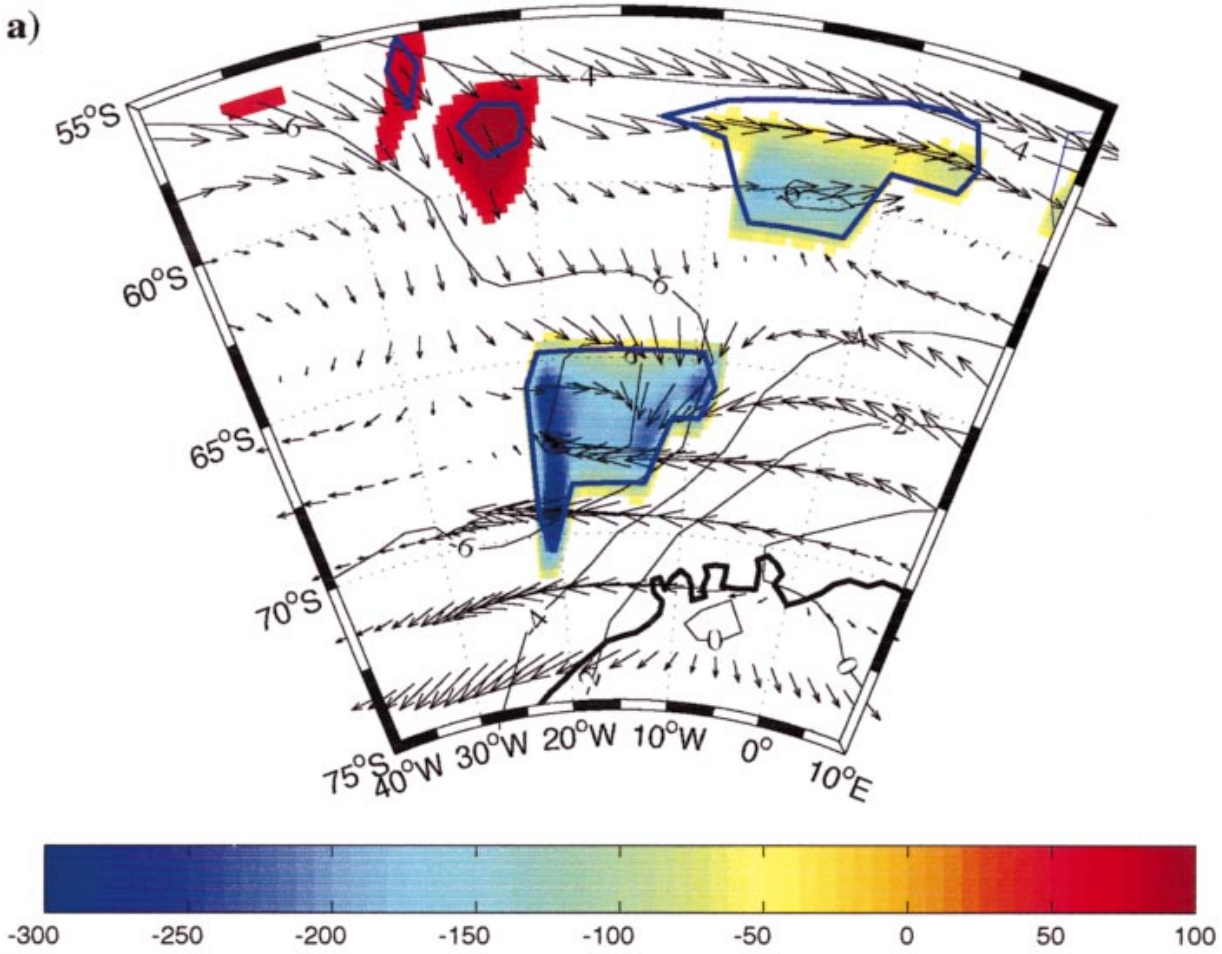

b)
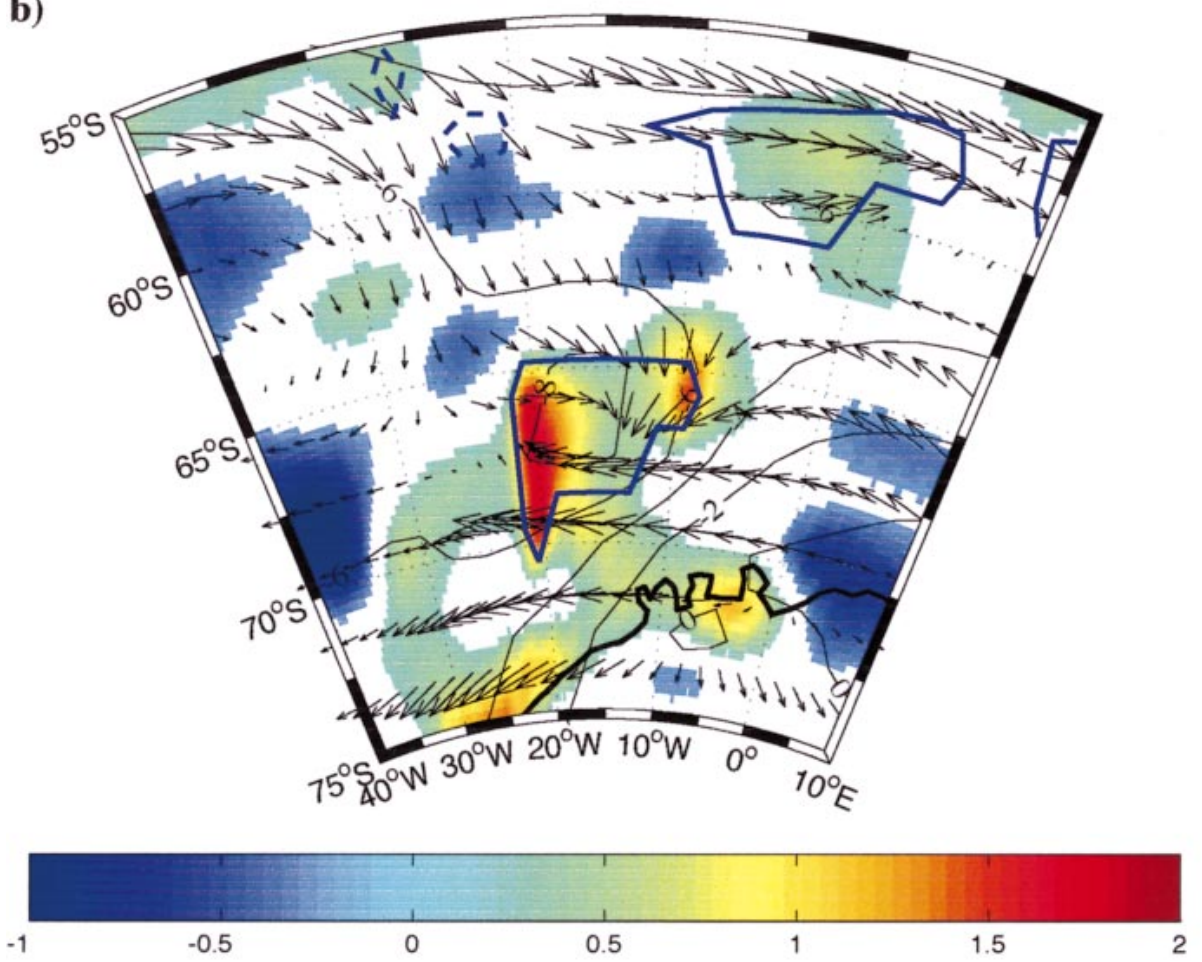

FIG. 3. The Aug 1976 monthly mean anomalies in (a) total turbulent heat flux field $\left(\mathrm{W} \mathrm{m}^{-2}\right)$ and (b) precipitation field $\left(\mathrm{mm} \mathrm{day}^{-1}\right)$ as compared to the 20-yr mean. Also shown are anomalies in the monthly mean sea level pressure field (black, mb), the monthly mean ice concentration field (blue, 50\%), and surface wind field (black, vectors). 
a)

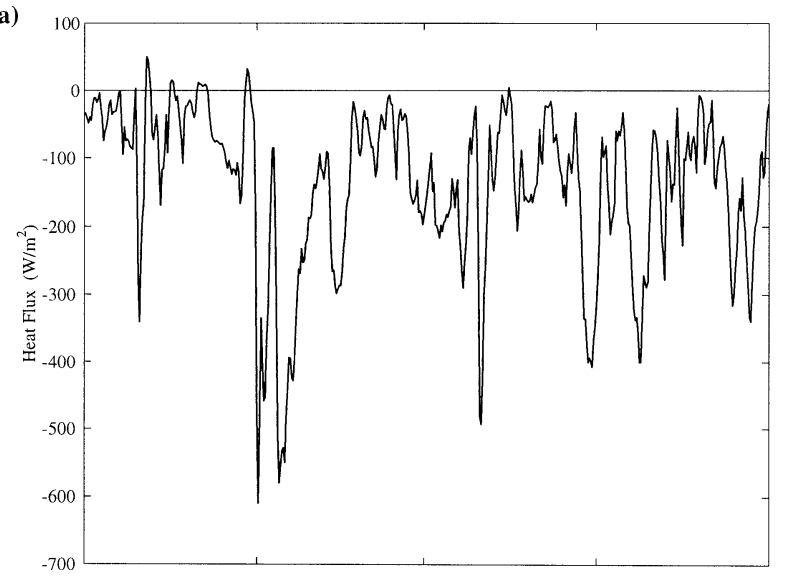

b)

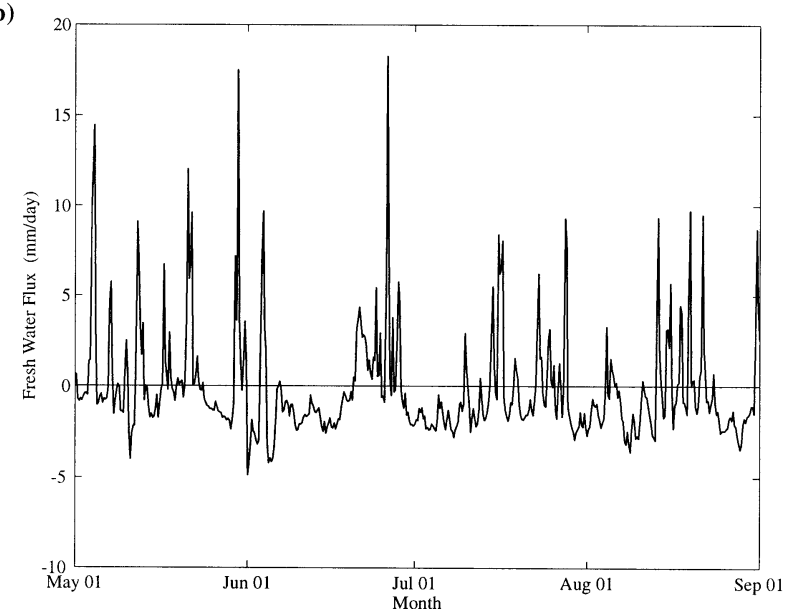

FIG. 4. Time series of the 6-hourly (a) total turbulent heat flux and

(b) freshwater flux at $67^{\circ} \mathrm{S}, 15^{\circ} \mathrm{W}$ during austral winter 1976.

would precipitate out resulting in the observed crosscorrelations in the 2-m air temperature and 10-m wind fields.

If one makes the assumption that regions of negative cross-correlation with the sea level pressure field identified in Fig. 6 are associated with low pressure systems, such as those shown in Fig. 5, then there is an important difference between the structures in Figs. 6a,b. Most importantly, Fig. 6a has a diffuse troughlike structure while Fig. 6b has a well-defined monopole structure. The two minima in the troughlike structure in Fig. 6a suggests that there may be two distinct locations where the low pressure systems that are associated with high heat flux events over the polynya have their centers. A month-by-month examination of cross-correlation between the sea level pressure field and the total turbulent heat flux over the polynya indicates that there indeed is a seasonal translation in the location of the centers of the low pressure systems. This is illustrated in Fig. 7 which shows the cross-correlation of sea level pressure and $10 \mathrm{~m}$ wind fields with total turbulent heat flux over the Weddell polynya for the months of June (Fig. 7a) and August (Fig. 7b). For simplicity, the complete fields are shown without regard for statistical significance. All the extrema are nevertheless statistically significant at the $95 \%$ level. In June, the location of the low pressure centers tends to be situated to the southeast over Antarctica. A strong high pressure center to the northwest results in a pressure gradient and southwesterly flow over the polynya. In contrast during August, the location of the low pressure centers tends to be situated to the northeast. High pressures to the southwest again result in a pressure gradient across the polynya-the difference being its orientation that results in southeasterly flow over the polynya. During the latter months of the year, the location of the low pressure centers again migrates to the southeast of the polynya. This migration is undoubtedly related to the seasonal movement in the ice edge and the concomitant movement in the region of maximum baroclinicty (King and Turner 1997).

\section{Atmospheric forcing of ocean convection within the polynya}

Ocean convection almost certainly occurred within the Weddell polynya and so it is of great interest to determine the impact that the air-sea interaction had on the density of the surface waters within the polynya. We will therefore use the reconstructed air-sea flux fields from the NCEP-NCAR reanalysis to determine the impact that the polynya had on the buoyancy of the surface waters. The time rate of change of this quantity, the so-called buoyancy flux $B$, is a function of the turbulent heat and freshwater and radiative fluxes across the air-sea interface and may be written as (Gill 1982)

$$
B=\frac{g \alpha}{\rho_{o} C_{p}}\left(Q_{S}+Q_{L}+Q_{R}\right)+\frac{g \beta S(P-E)}{\rho_{o}},
$$

where $Q_{S}, Q_{L}, Q_{R}$ are the sensible, latent, and net radiative fluxes; $P, E$ are the precipitation and evaporation rates; $\alpha, \beta$ are the thermal and haline expansion coefficients for seawater; and $g, \rho_{o}, C_{p}$ are the acceleration due to gravity, a reference density, and the specific heat for seawater.

A positive buoyancy flux implies an increase in buoyancy, or equivalently a decrease in density, of the surface waters. Given the different units for the heat and freshwater fluxes and the dependence of the various properties of seawater on the sea surface temperature $T$ and salinity $S$, it is not immediately evident from (1) what the relative importance of these forcings are to changes in surface buoyancy. An approach that assists in this determination is to ask the question: what heat flux is required to effect the same change to the buoyancy of the surface waters as occurs from a freshwater flux of $(P-E)$ ? This leads naturally to an expression of the freshwater forcing as a heat flux, $Q_{\mathrm{FW}}$, as follows:

$$
Q_{\mathrm{FW}}=\frac{\beta S C_{p}}{\alpha}(P-E) \text {. }
$$


a)
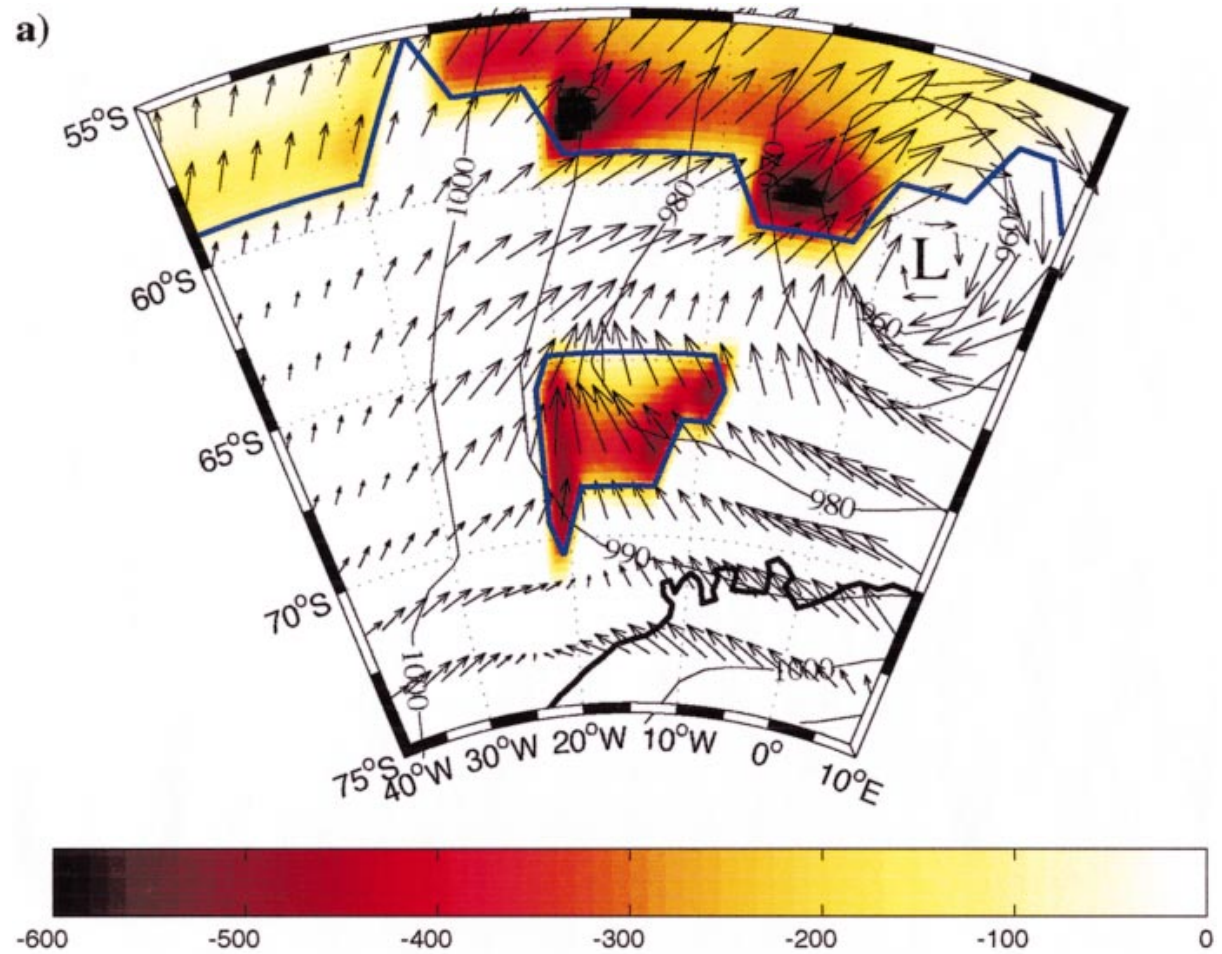

b)
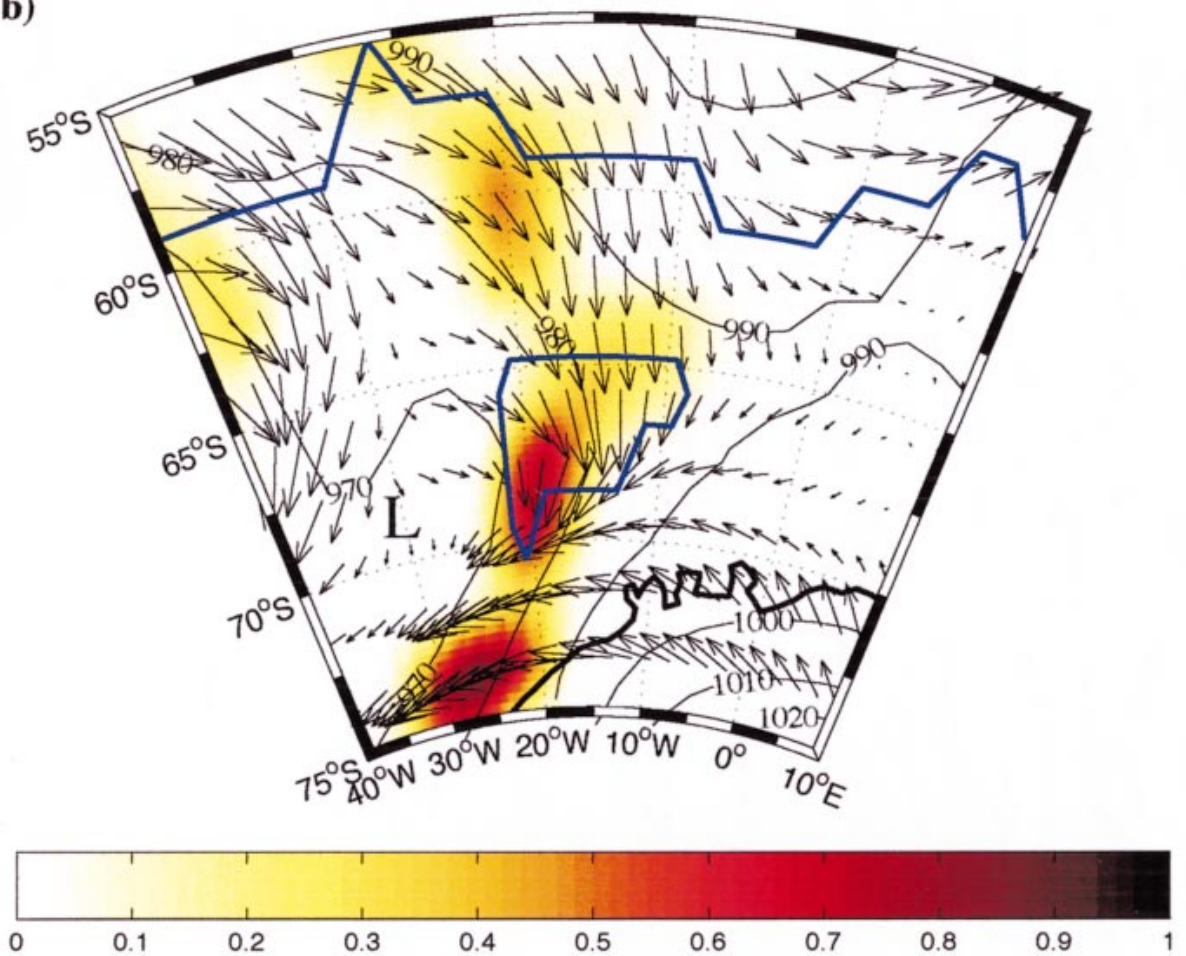

FIG. 5. (a) The total turbulent heat flux field $\left(\mathrm{W} \mathrm{m}^{-2}\right)$, sea level pressure (black, $\mathrm{mb}$ ), and 10-m wind vectors (black) for 1800 UTC 8 Aug 1976 and (b) the precipitation rate $\left(\mathrm{mm} \mathrm{h}^{-1}\right)$, sea level pressure (black, mb), and 10-m wind vectors (black) for 0600 UTC 19 Aug 1976. The heavy blue line indicates the $50 \%$ sea ice concentration isoline. 
a)
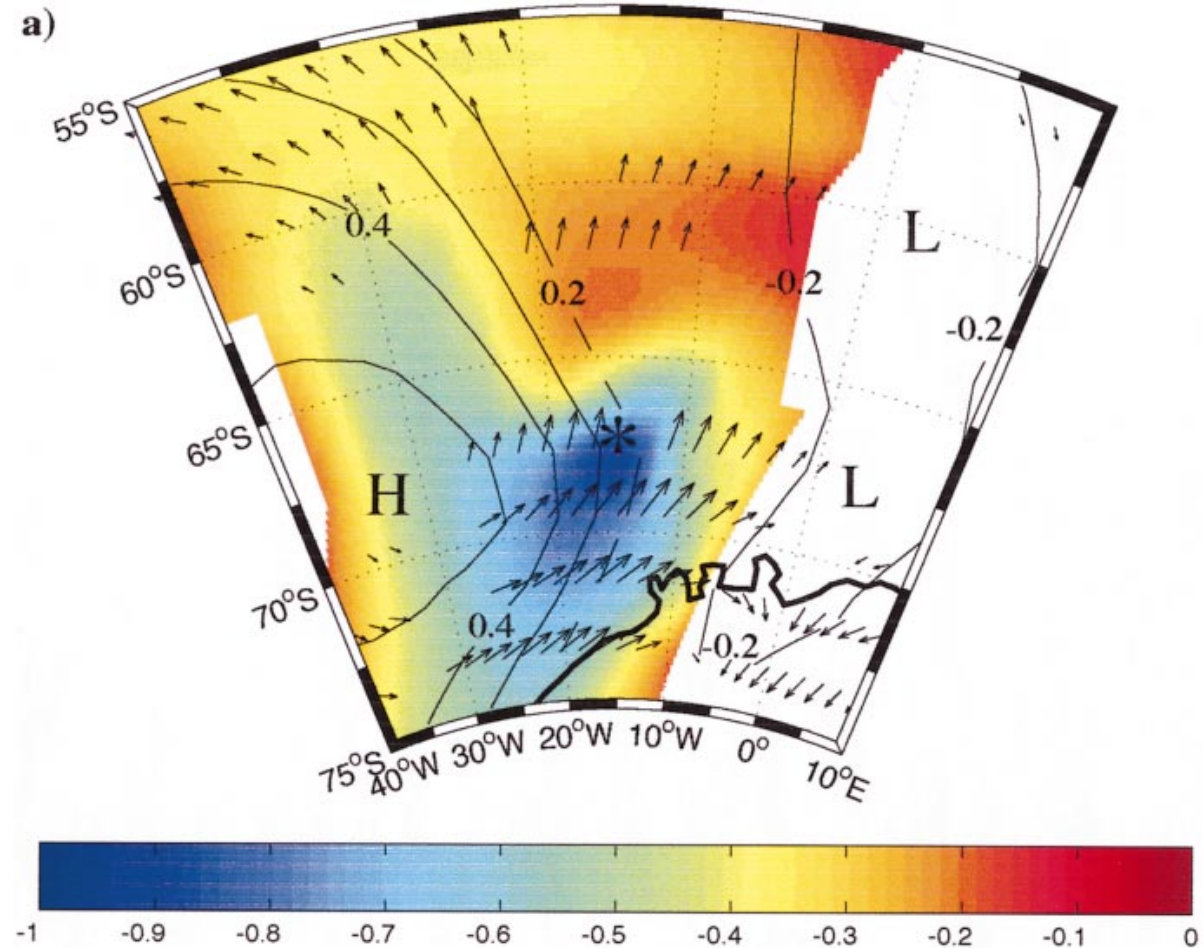

b)
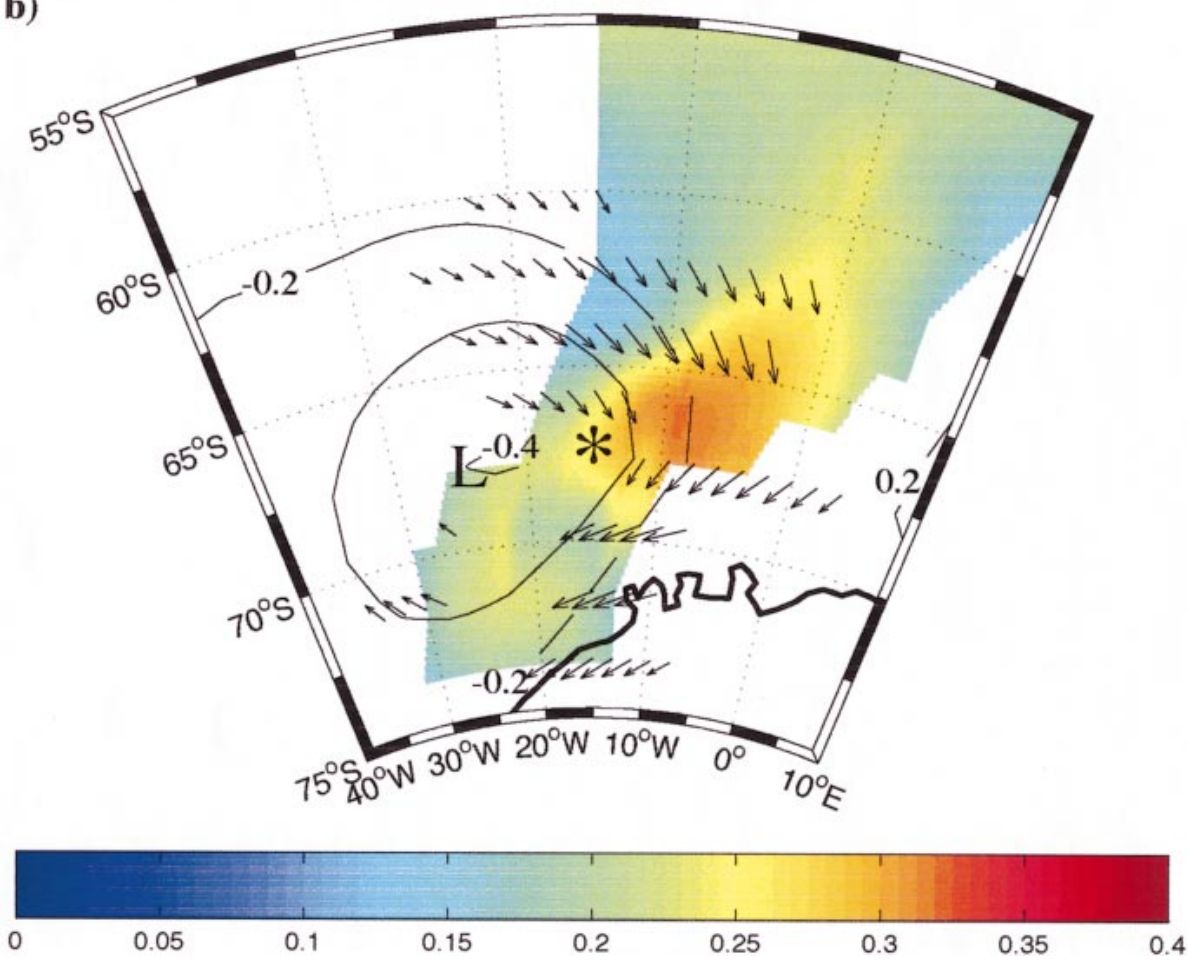

FIG. 6. Cross-correlation fields of the 2-m air temperature (shaded), slp (contours), and 10-m wind (vectors) with (a) the total turbulent heat flux into the atmosphere and (b) the total precipitation at $67^{\circ} \mathrm{S}, 15^{\circ} \mathrm{W}$, indicated by the asterisk, for the period of 1 May-30 Sep 1976 . Fields are only displayed at locations where the cross-correlation are statistically significant at the $95 \%$ confidence level. 

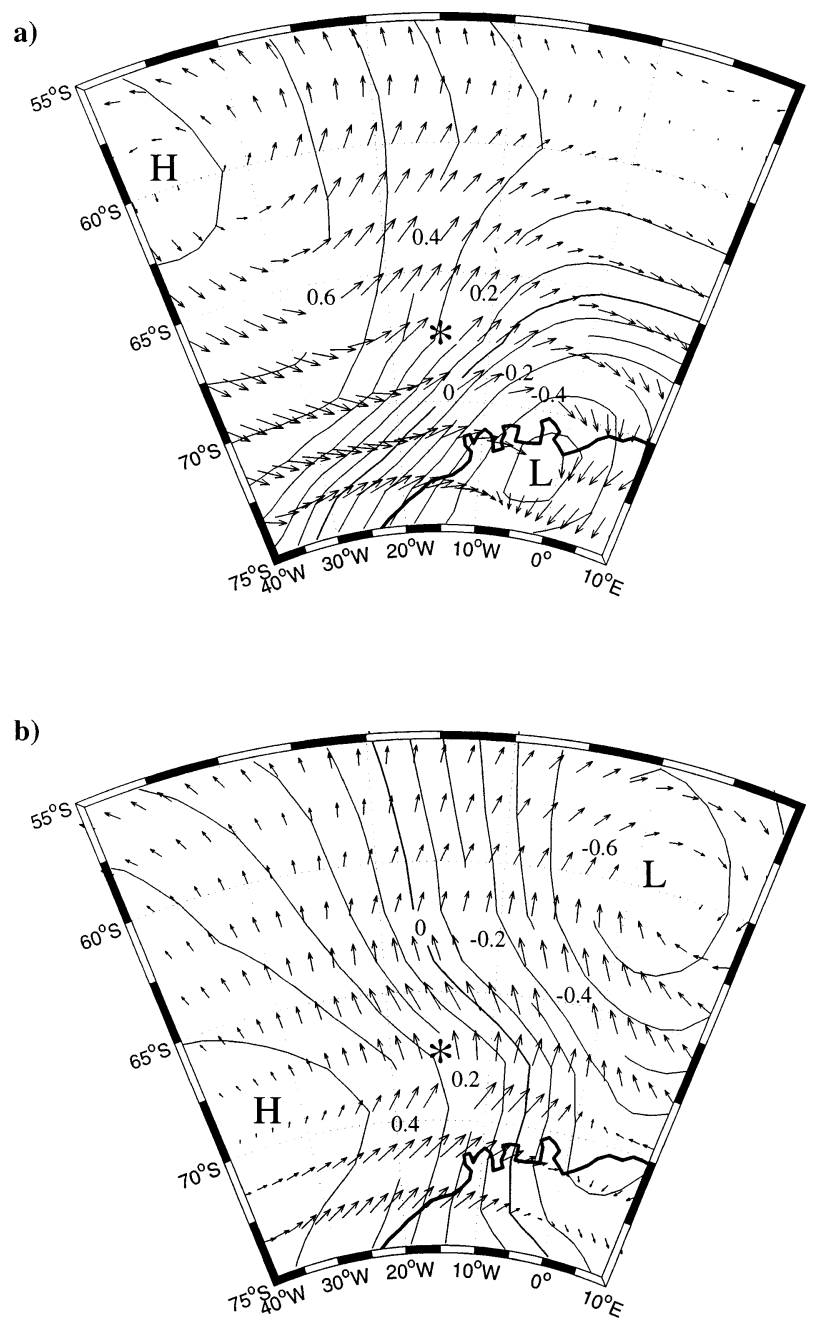

FIG. 7. Cross-correlation fields of the slp (contour) and 10-m wind (vectors) with the total turbulent heat flux into the atmosphere at $67^{\circ} \mathrm{S}, 15^{\circ} \mathrm{W}$, indicated by the asterisk, for the period (a) 1-30 Jun 1976 and (b) 1-31 Aug 1976.

The magnitude of $Q_{\mathrm{FW}}$ is a strong function of $T$ due to nonlinearity in the equation of state for seawater, which results in a reduction in the magnitude of the thermal expansion coefficient $\alpha$ at cold surface temperatures. The haline expansion coefficient $\beta$ does not experience such a strong dependency on $T$. From (2), one can see that this manifests itself as an increase in the magnitude of $Q_{\mathrm{FW}}$ for a fixed freshwater flux as the surface temperature decreases. This dependence is illustrated in Fig. 8. The impact of this nonlinearity is to increase the importance of the freshwater flux as a mechanism to change the buoyancy of the surface waters in regions of cold sea surface temperatures. Sea surface temperatures in the polynya have been estimated to be on the order of $-1^{\circ} \mathrm{C}$ (Gordon 1981; Huber 1989). At this temperature, Fig. 8 shows that the effective surface warming associated with a precipitation rate of $0.5 \mathrm{~mm}$ $\mathrm{h}^{-1}$ would have been on the order of $400 \mathrm{~W} \mathrm{~m}^{-2}$. From

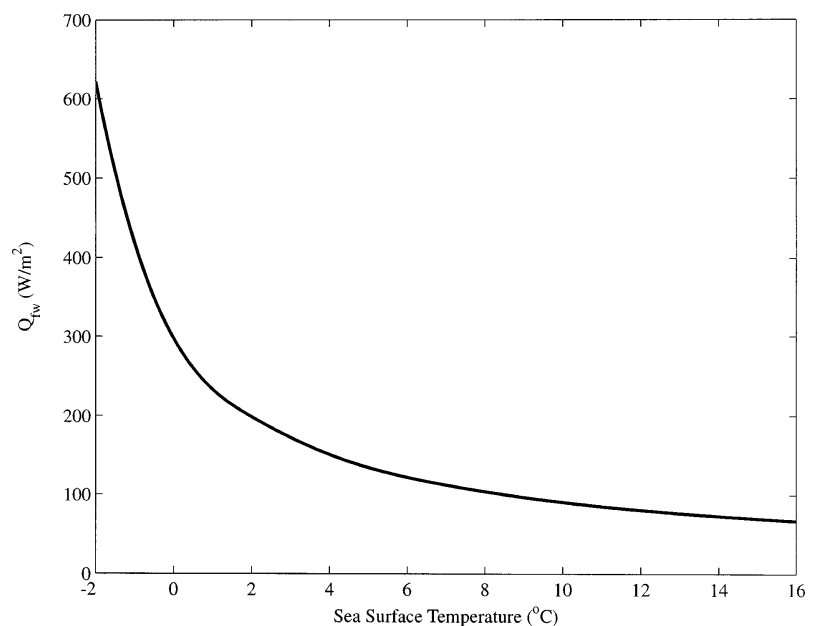

FIG. 8. Effective surface warming, $\mathrm{Q}_{\mathrm{FW}}$, as a function of sea surface temperature for a freshwater flux of $0.5 \mathrm{~mm} \mathrm{~h}^{-1}$. The surface salinity used for this calculation was 34.5 psu.

the data presented in Figs. 2 and 4, it is therefore clear that precipitation must have played an important role in determining the buoyancy of the surface waters within the polynya.

The buoyancy flux may then be written as

$$
B=\frac{g \alpha}{\rho_{o} C_{p}}\left(Q_{T}+Q_{\mathrm{FW}}+Q_{R}\right)
$$

where $Q_{T}=Q_{S}+Q_{L}$ is the total turbulent heat flux. Figure 9 shows a 6-hourly time series of the buoyancy flux $B$ and its components as defined in (3) at $67^{\circ} \mathrm{S}$, $15^{\circ} \mathrm{W}$ during austral winter 1976 . A surface salinity $S$ of 34.5 psu typical of modern winter conditions in the Weddell Sea, was used to calculate $B$. The results obtained were not sensitive to the particular value of $S$. For the sea surface temperature within the polynya, the decision was made to use a constant value of $-1^{\circ} \mathrm{C}$. This conservative value may be as much as $0.5^{\circ} \mathrm{C}$ warmer than actual values within the polynya (Gordon 1981) and thus would tend to underestimate the impact that precipitation has on $B$. Figure 9 a shows that $Q_{T}$ and $Q_{\mathrm{FW}}$ are usually of similar magnitude but typically of opposite signs. During the winter months, the net radiative flux is smaller in magnitude compared to the other two contributors to the buoyancy flux and does not exhibit the same degree of high-frequency variability. The buoyancy flux, Fig. 9b, which is proportional to the sum of these fluxes, is typically negative, indicating that the surface waters were becoming denser, thereby driving oceanic convection and Antarctic Bottom Water formation. Nevertheless there are periods when the field was positive, indicating that the freshwater flux due to precipitation was at times larger than the local cooling of the surface waters.

It is of interest to calculate the mean buoyancy loss experienced by the surface waters of the Weddell Sea as a result of the presence of the polynya. For the pur- 
a)

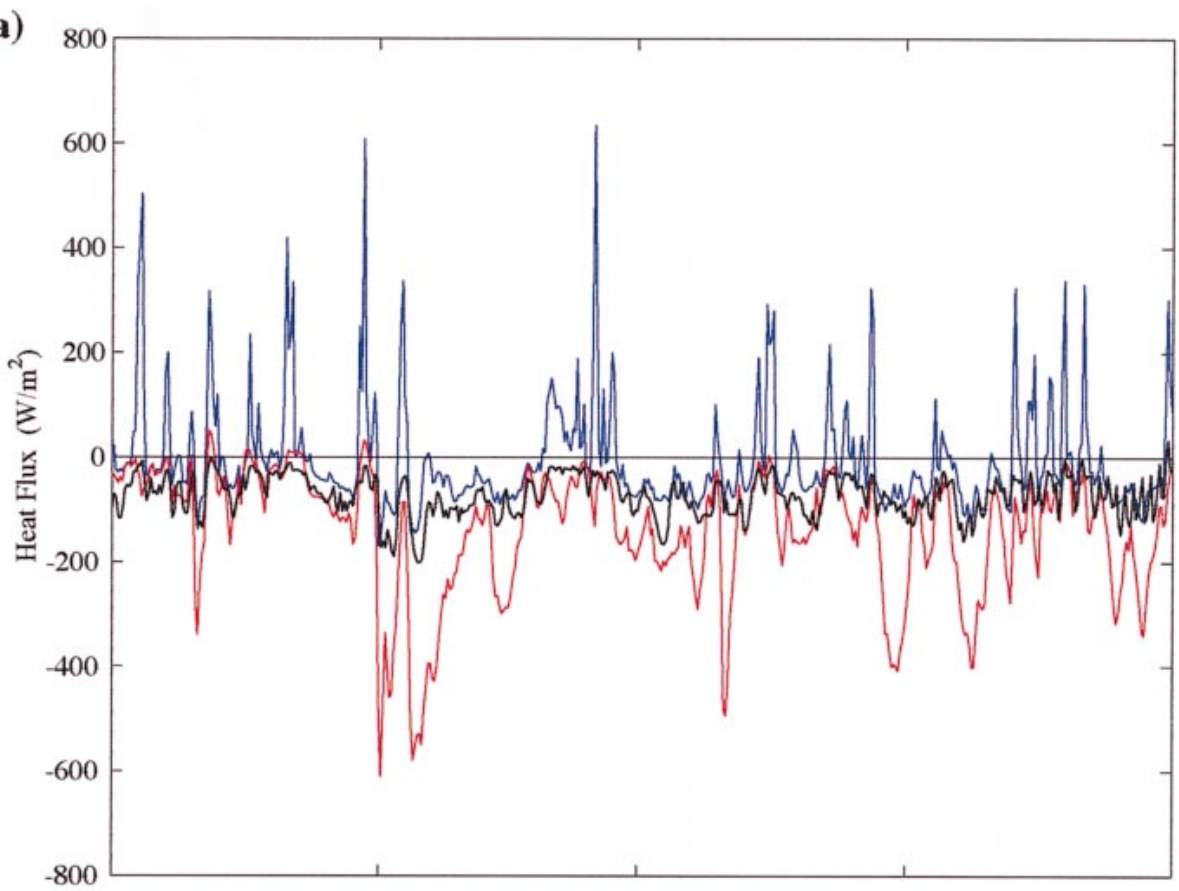

b)

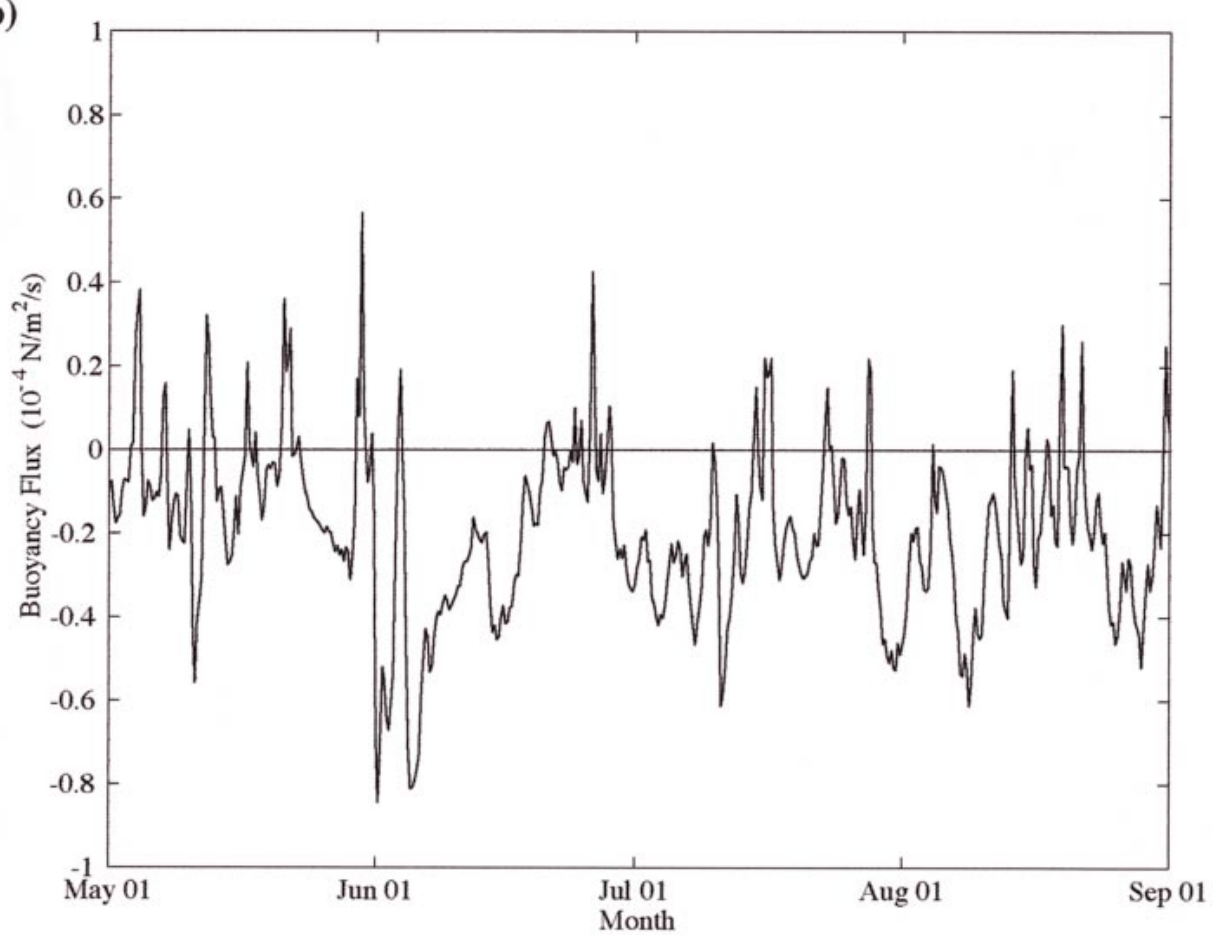

FIG. 9. Time series of the 6-hourly (a) total turbulent heat flux (dashed), freshwater flux expressed as a heat flux (solid), and net radiative flux (dotted). (b) Buoyancy flux at $67^{\circ} \mathrm{S}, 15^{\circ} \mathrm{W}$ as reconstructed from the NCEP-NCAR reanalysis during the austral winter of 1976. 
TABLE 1. Comparison of mean buoyancy flux and its components over the Weddell Polynya for the period 1 Mar-1 Oct. The freshwater flux is expressed in units of $\mathrm{W} \mathrm{m}^{-2}$ as discussed in the paper. For the NCEP-NCAR reanalysis, the standard deviations of the 6-hourly data about the means are also indicated in parentheses. Data in the column titled "Gordon" are from Gordon (1981).

\begin{tabular}{llll}
\hline \hline & Gordon & $\begin{array}{c}\text { NCEP-NCAR } \\
1975\end{array}$ & $\begin{array}{c}\text { NCEP-NCAR } \\
1976\end{array}$ \\
\hline $\begin{array}{c}\text { Total turbulent } \\
\text { heat flux } \\
\left(\mathrm{W} \mathrm{m} \mathrm{m}^{-2}\right)\end{array}$ & -136 & $-104(70)$ & $-100(74)$ \\
$\begin{array}{l}\text { Freshwater flux } \\
\left.(\mathrm{W} \mathrm{m})^{-2}\right)\end{array}$ & 25 & $-25(92)$ & $-5(103)$ \\
$\begin{array}{l}\text { Net radiative } \\
\text { flux } \\
\left(\mathrm{W} \mathrm{m}^{-2}\right)\end{array}$ & -6 & $-55(48)$ & $-50(50)$ \\
$\begin{array}{c}\text { Buoyancy flux } \\
\left(10^{-7} \mathrm{~m}^{2} \mathrm{~s}^{-3}\right)\end{array}$ & -0.106 & $-0.168(0.152)$ & $-0.141(0.170)$ \\
\hline
\end{tabular}

poses of this calculation, we have chosen 1 March-1 October as the period of integration. This corresponds to the period of time in which the buoyancy flux over the polynya was primarily negative. Table 1 shows results for both 1975 and 1976. For comparison, we have also used the estimates from Gordon (1981) to compute a mean buoyancy flux. They have been widely used in modeling studies of ocean convection within the polynya (Martinson et al. 1981; Motoi et al. 1987; Martinson 1991; Akitomo et al. 1995). Mean values of the three components of the buoyancy flux are also presented. Standard deviations of the 6-hourly data about the means are also shown. The air-sea fluxes in 1975 and 1976 were similar, with the only notable difference being that in 1976 the freshwater forcing was higher, indicating more precipitation fell during that year. The data indicate that the buoyancy flux, and each of its components, are all highly variable in time. A comparison with Gordon's estimates indicates that his estimate of the total turbulent heat flux is larger than that derived from the reanalysis while the freshwater flux is of the opposite sign. In addition, his estimate of the net radiative flux is significantly smaller in magnitude that than of the reanalysis. Although these discrepancies are somewhat self-canceling the net result is that the mean buoyancy flux derived from Gordon's estimates is 30\%$40 \%$ lower than that derived from the reanalysis.

\section{Conclusions}

A recent major climatic event was the occurrence of a very large region of open water or polynya in the ice pack in the Weddell Sea off Antarctica during the winters of 1974-76. Within the polynya, there was vigorous air-sea interaction that resulted in the formation of large amounts of cold and very dense water that has since flowed equatorward cooling the abyssal waters of the South Atlantic Ocean (Gordon 1978; Coles et al. 1996). In this paper, we have made use of NCEP-NCAR reanalysis products to provide the first quantitative details of the air-sea interaction associated with this event. The interaction was particularly intense with peak surface cooling in excess of $500 \mathrm{~W} \mathrm{~m}^{-2}$ and peak precipitation rates in excess of $1 \mathrm{~mm} \mathrm{~h}^{-1}$. The latter had an impact on the buoyancy of the surface waters as large as that associated with a surface warming in excess of $800 \mathrm{~W}$ $\mathrm{m}^{-2}$. The later result is an important one as it implies that precipitation should not be neglected as a forcing term in studies of oceanic convection in the Weddell Sea. This suggests that conclusions reached by Motoi et al. (1987) and Akitomo et al. (1995) may need to be reassessed as both of these studies neglected precipitation. The spatial distribution of surface cooling within the polynya suggests that the observed westward drift of the polynya (Carsey 1980) may have been enhanced by melting of ice on its western boundary due to more vigorous oceanic convection forced by the intense airsea interaction in this region.

The exchanges of heat and moisture across the airsea interface within the polynya were highly variable in time, with numerous distinct surface cooling and precipitation events. As a result of the nonlinear nature of air-sea interaction processes, high temporal resolution data (e.g., 6-hourly) are required to calculate accurate surface flux fields on monthly and longer timescales. Cross-correlation analysis suggests that these events were associated with coherent atmospheric weather systems, that is, extratropical cyclones. Martinson et al. (1981) in their model of ocean convection in the polynya attempted to include such variability in the air-sea fluxes by representing them as stochastic variations. Our results suggest that such random fluctuations probably do not accurately represent the variability in the atmospheric forcing that actually occurred. In addition the magnitude of the fluctuations that they used, $\pm 20 \%$, was significantly smaller than that suggested by the reanalysis data.

Evidence has been presented that the results from Gordon (1981) that have been used to represent the airsea interaction over the polynya significantly underestimated its magnitude. This is particularly true for the freshwater flux that appears to have the incorrect sign in Gordon (1981). The reconstructed integrated buoyancy flux over the winter months of both 1975 and 1976 exceed that of Gordon by $30 \%-40 \%$. This result implies that the oceanic convection that took place as a result of the existence of the polynya was significantly more vigorous than previously thought.

The surface forcing is necessary but not sufficient to reconstruct the ocean's response to the presence of the polynya. As has been shown by a number of authors (Jones and Marshall 1993; Visbeck et al. 1996; Alverson 1997; Legg et al. 1998), localized surface cooling of the ocean results in the development of lateral density gradients that leads to lateral mixing through the action of baroclinic eddies. In addition, advection of sea ice into the polynya and its subsequent melting was most likely a large source of fresh water that needs to be 
considered. It is interesting to note that our reconstructed surface forcing implies that the atmospheric convergence over the polynya would accentuate such advection. Without detailed knowledge of these lateral transports, an attempt to compute a buoyancy budget for the water column is not advisable.

Although this reconstruction has provided the first quantitative information on the air-sea interaction over the Weddell polynya, there are still significant uncertainties with respect to the larger-scale atmospheric and oceanic responses to this event. Our ability to assess the fidelity with which these analyses represent the air-sea interactions within such a polynya will not be answered until one is able to collect in situ data under similar environmental conditions.

Acknowledgments. We thank the reviewers and the editor for comments that have greatly improved this paper. The work described in this paper was supported by the Natural Sciences and Engineering Research Council of Canada and the Office of Naval Research. The authors would like to thank the NOAA Climate Diagnostics Center for providing access to the NCEPNCAR reanalysis data.

\section{REFERENCES}

Akitomo, K., T. Awaji, and N. Imasato, 1995: Open-ocean deep convection in the Weddell Sea: Two-dimensional numerical experiments with a nonhydrostatic model. Deep-Sea Res., 42, 53-73.

Alam, A., and J. Curry, 1995: Lead-induced atmospheric circulations. J. Geophys. Res., 100, 4643-4651.

Alverson, K., 1997: Mechanisms for lateral exchange with oceanic convection sites. J. Phys. Oceanogr., 27, 1436-1446.

— ocean deep convection. J. Phys. Oceanogr., 26, 2196-2213.

Carsey, F. D., 1980: Microwave observations of the Weddell Polynya. Mon. Wea. Rev., 108, 2032-2044.

CLIVAR, 1997: CLIVAR (Climate Variability and Predictability) Implementation plan. International CLIVAR Project Office. [Available on line at http://www.clivar.org/publications/other_pubs/ iplan/iip/contents.htm.]

Coles, V. J., M. S. McCartney, D. B. Olson, and W. M. Smethie Jr., 1996: Changes in Antarctic Bottom Water properties in the western South Atlantic in the late 1980s. J. Geophys. Res., 101, 89578970.

Cullather, R. I., D. H. Bromwich, and M. L. Van Woert, 1996: Interannual variations in Antarctic precipitation related to El NiñoSouthern Oscillation. J. Geophys. Res., 101, 19 109-19 118

, — - and - 1998: Spatial and temporal variability of Antarctic precipitation from atmospheric methods. J. Climate, 11, 334-368.

Dare, R. A., and B. W. Atkinson, 1999: Numerical modelling of atmospheric response to polynyas in the Southern Ocean sea ice zone. J. Geophys. Res., 104, 16 691-16 708.

DeCosmo, J., K. B. Katsaros, S. D. Smith, R. J. Anderson, W. A.
Oost, K. Bumke, and H. Chadwick, 1996: Air-sea exchange of water vapor and sensible heat: The Humidity Exchange Over the Sea (HEXOS) results. J. Geophys. Res., 101, 12 001-12 016.

Gill, A. E., 1982: Atmosphere-Ocean Dynamics. Academic Press, $662 \mathrm{pp}$.

Gordon, A. L., 1978: Deep Antarctic convection west of Maud Rise. J. Phys. Oceanogr., 8, 600-612.

- 1981: Seasonality of Southern Ocean sea ice. J. Geophys. Res., 86, 4193-4197.

, 1982: Weddell Deep Water variability. J. Mar. Res., 40, 199217.

, 1997: The AABW story: What, where, and how much and its global significance. Proc. ACSYS Conf. on Polar Processes and Global Climate, Oslo, Norway, ACSYS Project Office, 68-70.

— , and B. A. Huber, 1990: Southern Ocean winter mixed layer. J. Geophys. Res., 95, 11 655-11 683.

Hines, K. M., D. H. Bromwich, and G. J. Marshall, 2000: Artificial surface pressure trends in the NCEP-NCAR reanalysis over the Southern Ocean and Antarctica. J. Climate, 13, 3940-3952.

Huber, B. A., 1989: CTD and hydrographic data for Cruise ANT V/ 2 of R. V. Polarstern. Tech. Rep. LDGO-89-3.

Jones, H., and J. Marshall, 1993: Convection with rotation in a neutral ocean: A study of open ocean convection. J. Phys. Oceanogr., 23, 1009-1039.

Legg, S., J. McWilliams, and J. Gao, 1998: Localization of deep ocean convection by a mesoscale eddy. J. Phys. Oceanogr., 28, 944-970.

Kachigan, S. K., 1991: Multivariate Statistical Analysis: A Conceptual Introduction. 2d ed. Radius Press, 303 pp.

Kalnay, E., and Coauthors, 1996: The NCEP/NCAR 40-Year Reanalysis Project. Bull. Amer. Meteor. Soc., 77, 437-472.

King, J. C., and J. Turner, 1997: Antarctic Meteorology and Climatology. Cambridge University Press, 409 pp.

Martinson, D. G., 1991: Open ocean convection in the Southern Ocean. Deep Convection and Deep Water Formation in the Oceans, P. C. Chu and J. C. Gascard, Eds., Elsevier, 382 pp.

- P. D. Killworth, and A. L. Gordon, 1981: A convective model for the Weddell Polynya. J. Phys. Oceanogr., 11, 1741-1755.

McPhee, M. G., and Coauthors, 1996: The Antarctic Zone Flux Experiment. Bull. Amer. Meteor. Soc., 77, 1221-1232.

Moorthi, S., 1997: NWP experiments with a gridpoint semi-Lagrangian semi-implicit global model at NCEP. Mon. Wea. Rev., 125, $74-98$.

Motoi, T., N. Ono, and M. Wakatsuchi, 1987: A mechanism of the formation of the Weddell Polynya in 1974. J. Phys. Oceanogr., 17, 2241-2247.

Renfrew, I. A., G. W. K. Moore, P. Guest, and K. Bumke, 2002: A comparison of surface layer and surface turbulent flux observations over the Labrador Sea with ECMWF analyses and NCEP reanalyses. J. Phys. Oceanogr., 32, 383-400.

Smith, S. D., 1988: Coefficients for sea surface wind stress, heat flux, and wind profiles as a function of wind speed and temperature. J. Geophys. Res., 93, 15 467-15 472.

— R. D. Muench, and C. H. Pease, 1990: Polynyas and leads: An overview of physical processes and environment. J. Geophys. Res., 95, 9461-9479.

Walsh, J. E., and W. Chapman, 1998: Arctic cloud-radiation-temperature associations in observational data and atmospheric reanalyses. J. Climate, 11, 3030-3045.

Visbeck, M., J. Marshall, and H. Jones, 1996: Dynamics of isolated convective regions in the ocean. J. Phys. Oceanogr., 26, 17211734. 